\title{
Tooth Movement After Infrared Laser Phototherapy: Clinical Study in Rodents
}

\author{
Sabrina K. C. Gama, Ph.D.,,'2 Fernando A. L. Habib, Ph.D.,,2 Juliana S. de Carvalho Monteiro, D.D.S., \\ Gardênia M. Paraguassú, D.S., ${ }^{2}$ Telma Martins Araújo, Ph.D., Maria Cristina T. Cangussú, Ph.D., ${ }^{3}$ \\ and Antonio Luiz B. Pinheiro, Ph.D.,4,5
}

\begin{abstract}
Objectives: The aim of this research was to investigate the influence of low-power laser on tooth movement in rats. Background: Tooth movement is closely related to the process of bone remodeling. The biologic result, with the application of a force to the tooth, is bone absorption on the pressure side and neoformation on the traction side of the alveolar bone. The laser photobiomodulation is capable of providing an increase in cellular metabolism, blood flow, and lymphatic drainage. Methods: Thirty young-adult male Wistar rats weighing between 250 and $300 \mathrm{~g}$ were divided into two groups, control and experimental, containing 15 animals each. The animals received orthodontic devices calibrated to release a force of $40 \mathrm{~g} / \mathrm{F}$, with the purpose of moving the first upper molar mesially. Low-intensity laser, wavelength $790 \mathrm{~nm}$, was used in the experimental group; the dose was $4.5 \mathrm{~J} /$ $\mathrm{cm}^{2}$ per point, mesial and distal, on the palatal side, $11 \mathrm{~J} / \mathrm{cm}^{2}$ on the buccal side, and this procedure was repeated every $48 \mathrm{~h}$, totaling nine applications. The active movement was clinically evaluated after 7, 13, and 19 days. Results and conclusion: The results showed no statistically significant difference, $p=0.079$ (T0-T7), $p=0.597$ (T7-T13), and $p=0.550$ (T13-T19) between the laser and control groups on the amount of tooth movement in the different times evaluated. It may be concluded that laser phototherapy, with the parameters in the present study, did not significantly increase the amount of tooth displacement during induced orthodontic movement in rodents.
\end{abstract}

\section{Introduction}

$\mathbf{T}$ EeTH MOVE PHysiologically and constantly during the life span to maintain the harmony of the stomatologic system. Orthodontists considering these aspects developed a system of artificial forces to treat malocclusion and to restore the occlusion to its normal esthetics and functionality. ${ }^{1}$

Orthodontic treatment is based on the principle that if a prolonged force is applied to a tooth, the tooth will move itself as the alveolar bone is remodeling. ${ }^{2}$

The search for rapid and safe orthodontic movement has led to several studies involving drugs or alternative or complementary therapeutic approaches or both. ${ }^{3,4}$ Several studies using substances such as precursors of nitric oxide, prostacyclin, thromboxane $\mathrm{A}_{2}$, and tezosentan showed that tooth movement increases with their use. ${ }^{5-7}$ Conversely, in- terleukin-1, $\mathrm{TN} \alpha$; metalloproteinase, and $\gamma$-interferon may inhibit this movement. ${ }^{8-10}$

Previous reports found elsewhere on the literature have shown that the use of infrared (IR) laser light increases orthodontic movement. This effect has been attributed to the proliferation of periodontal cells, improved local circulation, as well as an increase of the activity of both osteoblasts and osteoclasts. ${ }^{11-14}$ The use of laser phototherapy (LPT) on bone has been well studied. ${ }^{15-17}$ Previous results found elsewhere on the literature are conflicting in regard to the amount of movement achieved because of the huge variation of the parameters used. ${ }^{13,17,18}$

Several aspects are important for the outcome of treatments involving the use of light sources. Most of the proposed protocols used different parameters, and this resulted in conflicting results. The choice of appropriate parameters is

\footnotetext{
${ }^{1}$ Centro de Ortodontia e Ortopedia Facial Prof. José Édimo Soares Martins, School of Dentistry, Federal University of Bahia (UFBA), Salvador, BA, Brazil.

${ }^{2}$ Laser Center, School of Dentistry, Federal University of Bahia (UFBA), Salvador, BA, Brazil.

${ }^{3}$ Dental Public Health, School of Dentistry, Federal University of Bahia (UFBA), Salvador, BA, Brazil.

${ }^{4}$ Universidade Camilo Castelo Branco, São José dos Campos, SP, Brazil.

${ }^{5}$ Instituto Nacional de Ciência e Tecnologia de Óptica e Fotônica, São Carlos, SP, Brazil.
} 
essential for the results of the treatment. These parameters include wavelength, power density, energy, and time and frequency of application. ${ }^{19}$

Laser phototherapy (LPT) may be used alone or with other techniques to stimulate tissues. It is known that the effects of LPT may not be the cause of healing. ${ }^{20-22}$ Some wavelengths possess therapeutic effects, and these are related to the use of adequate protocols. Laser light may affect cell metabolism in many ways and also may affect the secretion of $\beta$-endorphins, bradykinin, serotonin, and others. ${ }^{23}$ In orthodontics, LPT has been used as analgesic and a stimulant of bone repair. $^{21,24}$

We aimed to study the effect of the use of IR LPT on orthodontic movement in rodents.

\section{Methods}

After approval by the Animal Experimentation Ethics Committee of the School of Dentistry of the Federal University of Bahia, we obtained 30 healthy Rattus norvegicus young adult-male Wistar rats with an average age of 3 months and weighing between 250 and $300 \mathrm{~g}$. The animals were obtained from the Animal House of the School of Veterinary Medicine of the Federal University of Bahia and were kept at the Animal Experimentation Laboratory of the School of Dentistry of the Federal University of Bahia. The animals were kept in individual plastic cages lined with wood chips and maintained at $22^{\circ} \mathrm{C}$ in a day/night light cycle. The animals were fed a standard laboratory diet and had water available ad libidum. After a regular quarantine period, the animals were randomly distributed into two major groups with 15 animals in each. Group I acted as untreated control. The animals were subdivided into three subgroups according to the timing of the animal death $(7,13$, and 19 days).

Orthodontic movement was carried out by using the apparatus devised by King et al. ${ }^{25}$ The apparatus was installed on the upper arch of each animal. The force was applied by using a 0.010-inch wire (Morelli, Sorocaba, SP, Brazil) fixed to both extremities of one NiTi coil (Reflex Closed Coil Springs, light, $150 \mathrm{~g}$, 3 mm; TP Orthodontics, La Porte, IN). The apparatus was installed under general anesthesia. To fix the wire anteriorly, a hole was drilled with a round bur (KG Sorensen, São Paulo, SP, Brazil) between the two central incisors. The teeth were then conditioned with $37 \%$ phosphoric acid (Alpha Acid; DFL, Rio de Janeiro, RJ, Brazil) solution. A force of $40 \mathrm{~g} / \mathrm{F}$ was adjusted to the system with a dynamometer (25-250 dial type, HALDA, Halmstad, Sweden). The wire was marked on the lingual face and fixed with composite resin (Fill Magic Ortodôntico com Flúor; Vigodent, Rio de Janeiro, RJ, Brazil). Lower incisors were reduced in size to avoid damage to the apparatus during feeding. The first upper molar tooth was removed to eliminate mechanical interference (chewing) that could interfere with the desired mesial movement of the left upper first molar tooth. The apparatus used may be seen in Fig. 1.

LPT was carried out by using a diode laser (Laser Unit; Kondortech, São Carlos, SP, Brazil; $\lambda 790 \mathrm{~nm}, 40 \mathrm{~mW} \varphi$ $\sim 2 \mathrm{~mm}$, SAEF of $20 \mathrm{~J} / \mathrm{cm}^{2}$ per session). ${ }^{21,22}$ The treatment was carried out every other day during the experimental time, and the session dose (SAEF) was divided into three parts: $4.5 \mathrm{~J} / \mathrm{cm}^{2}$ applied both mesially and distally, and $11 \mathrm{~J} /$

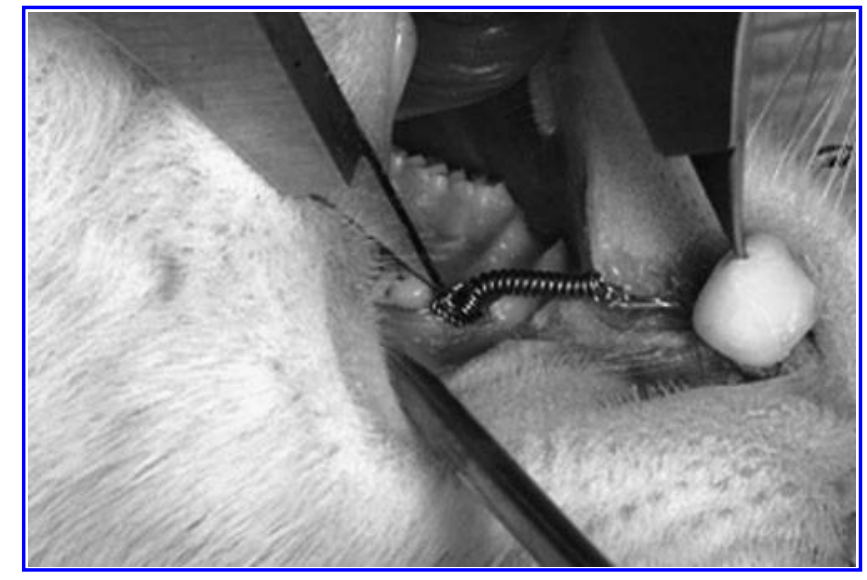

FIG. 1. System used for the experiment.

$\mathrm{cm}^{2}$ on the buccal side, the last applied extraorally because of the anatomic impossibility of delivering the dose precisely intraorally. On this application point, the dose was increased in $20 \%$ to compensate for losses due to transcutaneous application of the light. ${ }^{19}$ Animal death occurred after overdose of general anesthetics at days 7, 13, and 19 after installation of the apparatus. The animal weight did not change significantly during the experimental time in both groups.

The forces of the coil at the different times were calculated to verify whether they remained constant during the experiment. For this, Hooke's law was used, and this indicates that the deforming force is proportional to the elastic generation caused by the force.

Measurement of the distance between the most prominent point of the mesial surface of the first molar to the perforation on the resin bulk was performed in each animal immediately and at days 7,13 , and 19 . This procedure was used to assess the dislocation of the tooth and was carried out with a precision digital caliper (Beerendonk Caliper 78532; Aesculap, Tuttlingen, Germany).

Statistical analysis used the Kolmogorov-Smirnov test. Intergroup testing was carried out with Student's $t$ test. Significance level was set at $5 \%$.

\section{Results}

The data were normally distributed (Student's $t$ test). Table 1 shows the central tendency of measurements and dispersion of the data (in millimeters) of the distance between the reference points on the upper central incisor to the

Table 1. Central Tendency and Dispersion OF MOVEMENT DURING THE EXPERIMENT

\begin{tabular}{lllc}
\hline Time (days) & Group & Mean & Standard deviation \\
\hline 0 & Control & 14.711 & 0.683 \\
7 & Laser & 14.119 & 1.115 \\
7 & Control & 13.765 & 0.763 \\
13 & Laser & 13.307 & 1.131 \\
& Control & 13.331 & 0.857 \\
19 & Laser & 12.831 & 1.168 \\
& Control & 12.958 & 0.832 \\
& Laser & 12.386 & 1.320 \\
\hline
\end{tabular}


mesial surface of the upper first molar tooth on both groups during the experimental time. Table 2 shows the variation of the distance between these two points in relation to the time. The force of the coil at each time may be seen in Fig. 2 . Although the force was slightly higher in the irradiated group than in the Controls, this was not significant at T7 $(p=0.079) ; \mathrm{T} 13(p=0.455)$, and T19 $(p=0.914)$.

\section{Discussion}

Rodents (Rattus norvegicus) have been widely used in different experimental models of orthodontic movement because of their accelerated metabolism..$^{2,5,7,8,10,13,26-28}$ For the orthodontic movement to be efficient, some variables are essential, including the magnitude and duration of the force and the morphology and alveolar bone density. ${ }^{1}$ In our study, the initial force $(40 \mathrm{~g} / \mathrm{F})$ was applied continuously to induce more tooth movement. Similar forces have been used previously. ${ }^{27}$

It is known that LPT stimulates cells of the periodontal ligament, increases numbers of osteoclasts, and improves the local blood supply. These factors may be indicative that this modality of treatment may accelerate tooth movement during orthodontic treatment. ${ }^{29}$

The choice of the timing of the experiments was because most studies using the animal model of tooth movement use periods of observation ranging from 10 to 15 days. ${ }^{2,9,30-32} \mathrm{We}$ used the treatment at 48-h intervals, and with this time, we could assess the effect of the light during different phases of the movement.

In the present study, we measured the distance between the mesial point of the first molar and a reference point on the incisors and did not measure directly the space between the first and second molars. The main point that influenced our decision was that, when we mesially move a tooth, the adjacent tooth may also move because the presence of the transseptum periodontal fibers ${ }^{33}$ interferes with the measurement of the distance between the first and second molars.

Some previous reports on tooth movement used contralateral control ${ }^{3,12,18}$ and did not consider the systemic effect of $\mathrm{LPT}^{25}$ perhaps making comparison with our results tricky. We opted for not using contralateral controls as did previous reports in the literature. ${ }^{13,17}$ The protocol used on our study was also based on previous studies., ${ }^{3,11,13,18}$

Another aspect to consider was the site of application of the LPT. We opted for both intra- and extraoral application because of anatomic constraints. This may also further complicate comparisons with studies that used only intraoral applications. ${ }^{12,18}$

Table 2. Amount of Tooth Displacement DURING THE EXPERIMENT

\begin{tabular}{lccc}
\hline Time interval & Control $(\mathrm{mm}) \pm S D$ & Laser $(\mathrm{mm}) \pm S D$ & $\mathrm{p}^{\mathrm{a}}$ \\
\hline T0-T7 & $0.946 \pm 0.224$ & $0.812 \pm 0.169$ & 0.079 \\
T7-T13 & $0.434 \pm 0.189$ & $0.476 \pm 0.231$ & 0.597 \\
T13-T19 & $0.373 \pm 0.295$ & $0.445 \pm 0.353$ & 0.550 \\
T0-T13 & $1.379 \pm 0.294$ & $1.288 \pm 0.362$ & 0.455 \\
T0-T19 & $1.753 \pm 0.331$ & $1.733 \pm 0.601$ & 0.914 \\
\hline
\end{tabular}

astudent's $t$ test.

$\mathrm{SD}$, standard deviation.

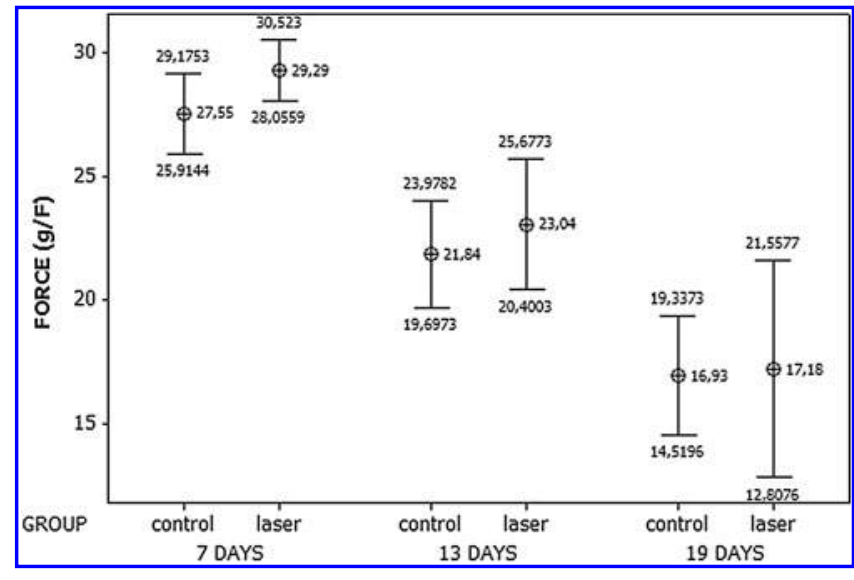

FIG. 2. Mean and $95 \%$ confidence interval of the force $(\mathrm{g} / \mathrm{F})$ of the coil at the different experimental groups and times.

It is known that prolonged force application on one tooth will result in its displacement, ${ }^{1,2,27,34-38}$ as seen in the present study. We found a significant reduction in the displacement between the beginning and the end of the treatment in both control and irradiated subjects $(p<0.001$ and $p=0.001)$, as seen in Table 1.

Our findings are indicative that the use of LPT did not significantly interfere with tooth displacement during orthodontic movement, as seen in Table 2, as mentioned previously. ${ }^{18}$ It also must be considered that this late report was based on human data and a different protocol. Conversely, different experimental setups have shown increased tooth displacement associated with the use of LPT. ${ }^{12,13}$ Our best result in this regard was found between $\mathrm{T} 0$ and $\mathrm{T} 7$ when LPT-treated subjects showed a smaller displacement than did the control.

The force used in the study seems not to have had a significant influence on the results, as no significant difference was found between the groups during the experimental time. We were not able to find any previous reports on the assessment of the degradation of the force during induced orthodontic movement in animals.

The fact that our results suggest that LPT does not significantly affect tooth displacement during orthodontic movement also considers previous reports that LPT possesses an analgesic effect. ${ }^{24,39}$ It may be possible that postactivation pain may be ameliorated by using LPT, without compromising movement. Another aspect that may also be considered is that LPT has been shown effective in bone repair after maxillary expansion, postactivation pain, and the healing of traumatic soft-tissue lesions caused by the orthodontic apparatus. ${ }^{40}$

A study from our group showed that LPT is capable of causing histologic changes related to the movement of teeth during orthodontic movement. Habib, ${ }^{15}$ similar to us, used nonirradiated subjects as controls because of the systemic effect of the LPT, different from other studies that did not consider this aspect or did not use it. The parameters used in the present study were based on work described previously in the literature. Habib showed a significant increase in the number of osteoblasts from days 7 to 13 after activation in LPT-treated animals. It was suggested that newly formed 
bone after LPT shows better quality than does nonirradiated bone and may lead to a quickening of the movement and alveolar bone remodeling. The results of Habib's study showed that LPT was able to increase the number of osteoblasts on the tension side. This aspect may lead to an improved capacity of the alveolar bone to remodel. An increased amount of collagen matrix was reported on the pressure side in irradiated subjects at both 13 and 19 days, when compared with nonirradiated animals. The same was also seen on the tension side. It is known that LPT has the capacity to stimulate both the secretion and proliferation of fibroblasts and consequent increased collagen matrix deposition. The fibroblasts of the periodontal ligament are actively involved in alveolar bone remodeling during orthodontic movement. ${ }^{41}$

The literature reports some previous works in which is suggested that laser treatment does interfere with tooth movement in rats, as this model features easy handling and standardization. $3,12,17,29,30,36,42$ Although we were not able to find a significant difference between irradiated and nonirradiated groups, we found that tooth displacement was becoming more similar during the experimental time (T0-T19; $p=0.914)$. It is possible that the rapid metabolism in the animal model may also have influenced the outcome of the study. It is possible that earlier observation times may result in different findings. It is also possible that the amount of energy was too high, as other studies using less energy reported acceleration of the movement. ${ }^{13}$

It may be concluded that LPT, using the parameters adopted in the present study, did not significantly increase the amount of teeth displacement during induced orthodontic movement in rodents

\section{Author Disclosure Statement}

No competing financial interests exist.

\section{References}

1. Norton, L.A., and Bustone, C.J. (1989). The Biology of Tooth Movement. Boca Raton, FL: CRC Press.

2. Bildt, M.M., Henneman, S., Maltha, J.C., Kuijpers-Jagtman, A.M., and Von der Hoff, J.W. (2007). CMT-3 inhibits orthodontic tooth displacement in the rat. Arch. Oral Biol. 52, 571578.

3. Goulart, C.S., Nouer, P.R.A., Martins, L.M., Garbin, I.U., and Lizarelli, R.F.Z. (2006). Photoradiation and orthodontic movement: experimental study with canines. Photomed. Laser Surg. 24, 192-196.

4. Sekhavat, A.R., Mousavizadeh, K., Pakshir, H.R., and Aslani, F.S. (2002). Effect of misoprostol, a prostaglandin $E_{1}$ analog, on orthodontic tooth movement in rats. Am. J. Orthod. Dentofacial Orthop. 122, 542-547.

5. Akin, E., Gurton, U., and Ölmez, H. (2004). Effects of nitric oxide in orthodontic tooth movement in rats. Am. J. Orthod. Dentofacial Orthop. 126, 608-614.

6. Drevensek, M., Sprogar, S., Boras, I., and Drevensek, G. (2006). Effects of endothelin antagonist tezosentan on orthodontic tooth movement in rats. Am. J. Orthod. Dentofacial Orthop. 129, 555-558.

7. Gurton, A.U., Akin, E., Sagdic, D., and Olmez, H. (2004). Effects of $\mathrm{PGI}_{2}$ and TXA $\mathrm{A}_{2}$ analogs and inhibitors in orthodontic tooth movement. Angle Orthod. 74, 526-532.
8. Dunn, M.D., Park, C.H., Kostenuik, P.J., Kapila, S., and Giannobile, W.V. (2007). Local delivery of osteoprotegerin inhibits mechanically mediated bone modeling in orthodontic tooth movement. Bone 41, 446-455.

9. Jäger, A., Zhang, D., Kawarizadeh, A., et al. (2005). Soluble cytokine receptor treatment in experimental orthodontic tooth movement in the rat. Eur. J. Orthod. 27, 1-11.

10. Mermut, S., Bengi, A.O., Akin, E., Kürkçü, M., and Karaçay, S. (2007). Effects of interferon-gamma on bone remodeling during experimental tooth movement. Angle Orthod. 77, 135-141.

11. Aihara, N., Yamaguchi, M., and Kasai, K. (2006). Low energy irradiation stimulates formation of osteoclast-like cells via RANK expression in vitro. Lasers Med. Sci. 21, 24-33.

12. Cruz, D.R., Kohara, E.K., Ribeiro, M.S., and Wetter, N.U. (2004). Effects of low-intensity laser therapy on the orthodontic movement velocity on human teeth: a preliminary study. Lasers Surg. Med. 35, 117-120.

13. Kawasaki, K., and Shimizu, N. (2000). Effects of low-energy laser irradiation on bone remodeling during experimental tooth movement in rats. Lasers Surg. Med. 26, 282-291.

14. Rody W.J. Jr., King, G.J., and Gu, G. (2001). Osteoclast recruitment to sites of compression in orthodontic tooth movement. Am. J. Orthod. Dentofacial Orthop. 120, 477-489.

15. Coombe, A.R., Ho, C-Tg, Philips, J.R., et al. (2001). The effects of low level laser irradiation on osteoblastic cells. Clin. Orthod. Res. 4, 3-14.

16. Fukuhara, E., Goto, T., Matayoshi, T., Kobayashi, S., and Takahashi, T. (2006). Optimal low-energy laser irradiation causes temporal $\mathrm{G}_{2} / \mathrm{M}$ arrest on rat calvarial osteoblasts. Calcif. Tissue Int. 79, 443-450.

17. Seifi, M., Shafeei, H.A., Daneshdoost, S., and Mir, M. (2007). Effects of two types of low-level laser wave lengths (850 and $630 \mathrm{~nm})$ on the orthodontic tooth movements in rabbits. Lasers Med. Sci. 22, 261-264.

18. Limpanichkul, W., Godfrey, K., Srisuk, N., and Rattanayatikul, C. (2006). Effects of low-level laser therapy on the rate of orthodontic tooth movement. Orthod. Craniofac. Res. 9, 38-43.

19. Tunér, J., and Hode, L. (2002). Laser Therapy: Clinical Practice and Scientific Background. Sweden: Prima Books, 571 p.

20. Damante, C.A., Greghi, S.L., Sant'Ana, A.C., Passanezi, E., and Taga, R. (2004). Histomorphometric study of the healing of human oral mucosa after gingivoplasty and low level laser therapy. Lasers Surg. Med. 35, 377-384.

21. Lopes, C.B., Pinheiro, A.L., Sathaiah, S., Duarte, J., and Martins, M.C. (2005). Infrared laser light reduces loading time of dental implants: a Raman spectroscopy study. Photomed. Laser Surg. 23, 27-31.

22. Silva Júnior, A.N., Pinheiro, A.L., Oliveira, M.G., Weismann, R., Ramalho, L.M., and Nicolau, R.A. (2002). Computerized morphometric assessment of the effect of low-level laser therapy on bone repair: an experimental animal study. J. Clin. Laser Med. Surg. 20, 83-87.

23. Amat, A., Rigau, J., Waynant, R.W., Ilev, I.K., Tomas J. and Anders, J.J. (2005). Modification of the intrinsic fluorescence and the biochemical behavior of ATP after irradiation with visible and near-infrared laser light. J. Photochem. Photobiol. B 81, 26-32.

24. Turhani, D., Scheriau, M., Kapral, D., Benesch, T., Jonke, E., and Bantleon, H.P. (2006). Pain relief by single low-level laser irradiation in orthodontic patients undergoing fixed appliance therapy. Am. J. Orthod. Dentofacial Orthop. 130, 371-377. 
25. King, G.J., Keeling, S.D., Mccoy, E.A., and Ward, T.H. (1991). Measuring dental drift and orthodontic tooth movement in response to various initial forces in adult rats. Am. J. Orthod. Dentofacial Orthop. 99, 456-465.

26. Hayashi, H., Konoo, T., and Yamaguchi, K. (2004). Intermittent 8-hour activation in orthodontic molar movement. Am. J. Orthod. Dentofacial Orthop. 125, 302-309.

27. Kale, S., Kocadereli, I., Atilla, P., and Asan, E. (2004). Comparison of the effects of 1,25 dihydroxycholecalciferol and prostaglandin $\mathrm{E}_{2}$ on orthodontic tooth movement. Am. J. Orthod. Dentofacial Orthop. 125, 607-614.

28. Sprogar, S., Volk, J., Drevensek, M., and Drevensek, G. (2007). The effects of TBC3214, a selective endothelin $\mathrm{ET}_{\mathrm{A}}$ receptor antagonist, on orthodontic tooth movement in rats. Eur. J. Orthod. 29, 605-608.

29. Yamaguchi, M., Fujita, S., Yoshida, T., et al. (2007). Lowenergy laser irradiation stimulates the tooth movement velocity via expression of M-CSF and c-fms. Orthod. Waves 66, 139-148.

30. Carlos, F., Cobo, J., Díaz-Esnal, B., et al. (2006). Orthodontic tooth movement after inhibition of cyclooxygenase-2. Am. J. Orthod. Dentofacial Orthop. 129, 402-406.

31. Kebsch, M., Wilkinson, M., Petocz, P., et al. (2007). The effect of fluoride administration on rat serum osteocalcin expression during orthodontic movement. Am. J. Orthod. Dentofacial Orthop. 131, 515-524.

32. Taweechaisupapong, S., Srisuk, N., Nimitpornsuko, C., et al. (2005). Evening primrose oil effects on osteoclasts during tooth movement. Angle Orthod. 75, 356-361.

33. Miyajima, K., and Nakamura, S. (1994). Distalization with "driftodontics." J. Clin. Orthod. 28, 393-394.

34. Götz, W., Kunert, D., Zhang, D., Kawarizadeh, A., Lossdörfer, S., and Jäger, A. (2006). Insulin-like growth factor system components in the periodontium during tooth root resorption and early repair processes in the rat. Eur. J. Oral Sci. 114, 318-327.

35. Orellana-Lezcano, M.F., Major, P.W., Mcneil, P.L., and Borke, J.L. (2005). Temporary loss of plasma membrane integrity in orthodontic tooth movement. Orthod. Craniofacial Res. 8, 106-113.
36. Ren, Y., Kuijpers-Jagtman, A.M., and Maltha, J.C. (2005). Immunohistochemical evaluation of osteoclast recruitment during experimental tooth movement in young and adult rats. Arch. Oral Biol. 50, 1032-1039.

37. Takahashi, I., Onodera, K., Nishimura, M., Mitnai, H., Sasano, Y., and Mitani, H. (2006). Expression of genes for gelatinases and tissue inhibitors of metalloproteinases in periodontal tissues during orthodontic tooth movement. J. Mol. Hist. 37, 333-342.

38. Wagle, N., Do, N.N., Yu, J., and Borke, J.L. (2005). Fractal analysis of the PDL-bone interface and implications for orthodontic tooth movement. Am. J. Orthod. Dentofacial Orthop. 127, 655-661.

39. Sekine, A., Yamamoto, A., Kobayashi, K., et al. (2003). Effects of the Nd:YAG laser on the pain associated with tooth movement. Int. Cong. Series 1248, 465-469.

40. Sarver, D. M., and Yanosky, M. (2005). Principles of cosmetic dentistry in orthodontics, part 2: soft tissue laser technology and cosmetic gingival contouring. Am. J. Orthod. Dentofacial Orthop. 127, 85-90.

41. Habib, F.A.L. (2008). Alterações teciduais decorrentes da fotobiomodulação laser no movimento dentário induzido em ratos. Salvador, Bahia, Brazil: Universidade Federal da Bahia. PhD thesis. $95 \mathrm{p}$.

42. Youssef, M., Ashkar, S., Hamade, E., et al. (2008). The effect of low-level laser therapy during orthodontic movement: a preliminary study. Lasers Med. Sci. 23, 27-33.

Address correspondence to: Antonio Luiz Barbosa Pinheiro Laser Center Faculdade de Odontologia Universidade Federal da Bahia Av. Araújo Pinho, 62, Canela Salvador, BA, CEP 40140-110

Brazil

E-mail: albp@ufba.br 
